\title{
BALANÇO DE RADIAÇÃO POR SENSORIAMENTO REMOTO EM BACIA HIDROGRÁFICA DA ZONA DA MATA NORDESTINA
}

\section{LEIDJANE MARIA MACIEL DE OLIVEIRA ${ }^{1}$, SUZANA MARIA GICO LIMA MONTENEGRO ${ }^{1}$, BERNARDO BARBOSA DA SILVA ${ }^{1}$, ALBERT EINSTEIN SPÍNDOLA SARAIVA DE MOURA ${ }^{2}$}

${ }^{1}$ Universidade Federal de Pernambuco (UFPE), Departamento de Engenharia Civil, Recife, PE, Brasil

${ }^{2}$ Instituto Federal de Educação, Ciência e Tecnologia da Paraíba (IFPB), Departamento de Formação Geral, Cajazeiras, PB, Brasil

leidjaneoliveira@hotmail.com, suzanam@ufpe.br, bbdasilva.ufpe@gmail.com, albert.moura@ifpb.edu.br

Recebido Junho de 2013 - Aceito Junho de 2014

\section{RESUMO}

Este trabalho objetivou determinar o balanço radiativo na bacia hidrográfica do rio Tapacurá - PE, área com presença intensa de nebulosidade, por meio de produtos MODIS dos satélites Terra (MOD11A1 e MOD09GA) e Aqua (MYD11A1 e MYD09GA). Instalou-se uma estação meteorológica experimental no período de janeiro/2010 a agosto/2011, destinada ao monitoramento de dados meteorológicos complementares ao processamento do saldo radiativo, além do cômputo in loco do mesmo. O saldo de radiação instantâneo estimado com os produtos MODIS situou-se entre 400 e $700 \mathrm{~W} \mathrm{~m}^{-2}$, com maiores valores registrados no reservatório do Tapacurá e os menores nas áreas urbanas. Já o saldo de radiação diário estimado variou de 95,4 a 157,5 $\mathrm{W} \mathrm{m}^{-2}$, com média de $125,4 \mathrm{~W} \mathrm{~m}^{-2}$. As diferenças entre o saldo de radiação medido na estação experimental (área de pastagem) e o estimado pelos produtos MODIS, resultaram em Diferença Absoluta Média, Diferença Relativa Média e Raiz da Diferença Quadrática Média, com valores de $122,4 \mathrm{~W} \mathrm{~m}^{-2}, 30,1 \%$ e $140,7 \mathrm{~W} \mathrm{~m}^{-2}$, respectivamente, para o saldo de radiação instantâneo, e $7,4 \mathrm{~W} \mathrm{~m}^{-2}, 5,8 \%$ e $9,7 \mathrm{~W} \mathrm{~m}^{-2}$, para o saldo de radiação diário. Concluiu-se que não obstante a intensa presença de nuvens na região foi possível obter o saldo radiativo na bacia do rio Tapacurá - PE, com base em produtos MODIS, onde os resultados foram compatíveis com outros estudos, confirmando a eficiência na aplicabilidade da técnica.

Palavras-chave: Radiação solar; MODIS; Albedo; Saldo de radiação.

\section{ABSTRACT: BALANCE OF RADIATION BY REMOTE SENSING OVER THE HYDROGRAPHIC} BASIN OF NORTHEASTERN MATA ZONE

This study aimed to determine the radiation balance in the basin of Tapacurá river - PE, an area with intense presence of cloudiness, through MODIS products of Terra satellites (MOD09GA and MOD11A1) and Aqua (MYD11A1 and MYD09GA). For the in situ balance radiation calculation and for the monitoring of meteorological data required for radiation balance processing, a weather station was installed and operated during the experimental period from January/2010 to August/2011. The instantaneous net radiation estimated with MODIS products were between 400 and $700 \mathrm{~W} \mathrm{~m}^{-2}$, the higher values were recorded in the Tapacurá reservoir and the smaller on urban areas. The estimated daily net radiation ranged from 95.4 to $157.5 \mathrm{~W} \mathrm{~m}^{-2}$, with an average of $125.4 \mathrm{~W} \mathrm{~m}^{-2}$. The differences between the net radiation measured at the experimental station (grazing area) and estimated by MODIS products, resulted in Mean Absolute Difference, Mean Relative Difference and Root Mean Squared Difference values of $122.4 \mathrm{~W} \mathrm{~m}^{-2}, 30,1 \%$ and $140.7 \mathrm{~W} \mathrm{~m}^{-2}$ respectively for the instantaneous net radiation, and $7.4 \mathrm{~W} \mathrm{~m}^{-2}, 5.8 \%$ and $9.7 \mathrm{~W} \mathrm{~m}^{-2}$ for the daily net radiation. It is concluded that despite the intense presence of clouds in the region it was possible to obtain the balance radiation on the Tapacurá River Basin - PE by MODIS based products, consistent with other studies results, confirming the efficiency on the technique applicability.

Keywords: Solar radiation; MODIS; Albedo; Net radiation. 


\section{INTRODUÇÃO}

O saldo de radiação $(\mathrm{Rn})$ exerce um papel fundamental nos processos de troca de calor e massa na baixa troposfera (Silva et al., 2005a), uma vez que se constitui no principal responsável pelo aquecimento do solo, do ar e, principalmente, pela evapotranspiração da vegetação nativa e de culturas agrícolas. Essa variável é essencial em estudos do balanço de energia (Bastiaanssen et al., 2005; Bisht et al., 2005; Allen et al., 2007; Anderson et al., 2012; Silva et al., 2012), sendo de grande importância no monitoramento do clima, previsão de tempo, modelagem hidrológica e meteorologia agrícola.

$\mathrm{O} \mathrm{Rn}$ pode ser medido por meio de saldos radiômetros, que não são usualmente empregados em estações meteorológicas convencionais e automatizadas, uma vez que têm custo elevado e suas medições não possibilitam pesquisas com resultados em escala regional. (Gomes et al., 2009; Di Pace et al., 2008). Medições realizadas por sensores orbitais, disponibilizados gratuitamente, a exemplo do Mapeador Temático Landsat 5 e MODIS, reúnem alta cobertura espacial e, consequentemente, possibilitam estudos regionalizados com baixo custo operacional. No entanto, possuem a desvantagem do impedimento causado pela presença de nuvens e a frequência de revisita dos sensores que pode ser de apenas 16 dias (caso dos satélites Landsat), ou de 1 a 2 dias, caso do Terra e Aqua.

A avaliação do saldo radiativo via sensoriamento remoto depende fundamentalmente do albedo, da temperatura da superfície, da radiação solar global e das emissividades da superfície e da atmosfera. Por essa razão há estudos que tratam especificamente do albedo (Liang, 2000; Silva et al., 2005a; Bezerra et al., 2011), da temperatura da superfície (Oliveira et al., 2012; Araújo e Di Pace, 2010), da radiação solar global (Zillman, 1972; Di Long et al., 2010), da emissividade atmosférica (Prata, 1996; Kruk et al., 2010; Santos et al., 2011) e da emissividade da superfície (Muñoz-Jiménez et al., 2006; Jin e Liang, 2006).

O sensor Moderate Resolution Imaging Spectroradiometer (MODIS) encontra-se a bordo dos satélites Terra e Aqua, dispõe de 36 bandas com cobertura espectral de 0,4 a 14,40 $\mu \mathrm{m}$, com resolução espacial de $250 \mathrm{~m}, 500 \mathrm{~m}$ e $1.000 \mathrm{~m}$, resolução radiométrica de 12 bits e resolução temporal diária. Há vários produtos elaborados com base nas medições da radiância de suas 36 bandas espectrais, muitos dos quais são disponibilizados em mosaicos (tiles), correspondentes a uma área georreferenciada com lados de $1.200 \times 1.200 \mathrm{~km}$ (Anderson et al., 2003). Os produtos MOD11A1 e MYD11A1, respectivamente derivados do MODIS Terra e Aqua, disponibilizam doze camadas com resolução espacial de $1 \mathrm{~km}$ e dados da superfície terrestre, entre eles a temperatura da superfície terrestre, a hora local de passagem do satélite e emissividades que podem ser utilizadas para pesquisas na estimativa de processos de modificação da superfície da Terra referente à Hidrologia, Climatologia, Ecologia e Biologia. Enquanto que os produtos MOD09GA e MYD09GA, do MODIS Terra e Aqua, respectivamente, reúnem camadas com resoluções espaciais de $1.000 \mathrm{~m}$ (sete camadas, com uma relativa ao ângulo zenital solar) e $500 \mathrm{~m}$ (nove camadas, sendo sete de reflectância da superfície), que são utilizadas no cômputo do albedo e diversos índices de vegetação.

Muitos estudos têm sido realizados com o propósito de determinar Rn instantâneo e/ou diário com sensores orbitais. Podem ser destacadas as pesquisas de Bisht et al. (2005, 2010), Ataíde et al. (2006), Tang e Li (2008), Jin et al. (2011), Santos et al. (2011), Lima et al. (2012) e Ruhoff et al. (2012), que fizeram uso de produtos MODIS em estudos de balanços de radiação e/ou de energia. Já Allen et al. (2007), Gomes et al. (2009) e Silva et al. $(2005 b, 2011)$ realizaram balanço de radiação com imagens TM Landsat 5.

A bacia hidrográfica do rio Tapacurá tem fator preponderante na gestão dos recursos hídricos e naturais do estado de Pernambuco, principalmente para a Região Metropolitana do Recife, uma vez que é manancial para abastecimento público de mais de um milhão de habitantes, contribuindo com mais de $25 \%$ da água consumida, por meio do reservatório da barragem do Tapacurá. Entretanto, sua localização no Litoral e Zona da Mata da região Nordeste do Brasil, representa um grande desafio quanto à determinação de fluxos de energia e massa com a utilização de imagens orbitais, em virtude da presença intensa de nebulosidade.

Neste sentido, este trabalho teve por objetivo avaliar o saldo de radiação instantâneo e diário na bacia hidrográfica do rio Tapacurá, estado de Pernambuco, por meio de produtos MODIS e dados meteorológicos complementares.

\section{MATERIAL E MÉTODOS}

A bacia do rio Tapacurá é uma sub-bacia do rio Capibaribe, estado de Pernambuco, integrante da Rede de Hidrologia do Semiárido (REHISA), com área de drenagem de aproximadamente $480 \mathrm{~km}^{2}$, estando localizada entre as coordenadas $35^{\circ} 05^{\prime}$ e $35^{\circ} 30^{\prime}$ de longitude Oeste e $07^{\circ} 58^{\prime}$ e $08^{\circ} 13^{\prime}$ de latitude Sul. Os solos da bacia são predominantemente do tipo Argissolo Vermelho seguido do Argissolo Amarelo. O relevo está em sua maior parte constituído por colinas e cristas, com $45,65 \%$ da área total da bacia apresentando declividade entre 0 e $9 \%$. A sua paisagem é composta por remanescentes da Mata Atlântica e alguns remanescentes de Caatinga. Apresenta áreas tanto da Zona da Mata Úmida como do Agreste Subúmido e o clima dominante da bacia é o As', conforme classificação climática de Köeppen. O período chuvoso da bacia posiciona-se entre os meses de março a julho, com precipitação pluviométrica 
anual média de $1.017 \mathrm{~mm}$, temperatura média mensal oscilando entre 23,7 e $27,0^{\circ} \mathrm{C}$, enquanto a umidade relativa do ar, durante os meses de maio a agosto, é superior a 75\% (Duarte et al., 2007; Oliveira et al., 2012).

O período de estudo está compreendido ente os meses de janeiro/2010 até agosto/2011. Instalou-se no interior da bacia uma estação meteorológica automatizada experimental $\left(08^{\circ} 05^{\prime} 19^{\prime \prime} \mathrm{S}, 35^{\circ} 14^{\prime} 56 \mathrm{~W}\right.$ e $\left.143 \mathrm{~m}\right)$, em extensa área de bordadura compreendendo pastagem de capim-lucas (Sporobulus Indicus), equipada com sensores de temperatura e umidade relativa do ar (termohigrômetro, modelo HMP45C da Vaisala Inc., Finlândia), saldo de radiação (saldo radiômetro modelo NR-LITE da Kipp e Zonen, Holanda), radiação solar global (piranômetro modelo CS300 da Kipp e Zonen, Holanda) e precipitação (pluviômetro modelo TB4 da Campbell Scientific, Estado Unidos). Os sensores foram acoplados a dois sistemas de aquisição de dados CR-1000 da Campbell Scientific programados para efetuar leitura dos sensores a cada 5 segundos e extrair médias a cada 30 minutos. Quinzenalmente foram realizadas manutenções dos sensores (limpeza e inspeção de funcionamento), ocasião em que se efetuava a coleta dos dados armazenados.

Os produtos MODIS (MOD11A1, MYD11A1, MOD09GA e MYD09GA) empregados na pesquisa foram adquiridos gratuitamente no Global Visualization Viewer (GLOVIS) da United States Geological Survey (USGS) pelo site http:/glovis.usgs.gov, referente ao tile h14 v09, com as imagens disponibilizadas no formato Hierarchical Data Format (HDF). O critério de seleção das imagens foi o que assegurasse ao menos $70 \%$ de pixels da bacia sem presença de nuvens, o que resultou na seleção de seis dias do ano de 2010 (dia sequencial do ano (DSA): 69, 120, 127, 184, 227 e 246) e seis em 2011 (DSA: 76, $96,112,133,151$ e 171). Para manuseio, recorte, empilhamento e álgebra entre as imagens utilizou-se o software Erdas Imagine e para montagem final dos layouts o ArcGis.

O saldo de radiação instantâneo à superfície - Rn (W $\mathrm{m}^{-2}$ ) foi estimado pela seguinte equação (Allen et al., 2007; Silva et al., 2012):

$$
R n=R_{O C, I N C}(1-\alpha)+R_{O L, A T M}-R_{O L, E M I}-\left(1-\varepsilon_{0}\right) \mathrm{R}_{\mathrm{OL}, \mathrm{ATM}}
$$

em que $\mathrm{R}_{\mathrm{OC} \text {,INC }}$ é a radiação de onda curta incidente $\left(\mathrm{W} \mathrm{m}^{-2}\right)$, $\mathrm{R}_{\mathrm{OL}, \mathrm{ATM}}$ é a radiação de onda longa emitida pela atmosfera na direção da superfície ( $\mathrm{W} \mathrm{m}^{-2}$ ), $\mathrm{R}_{\mathrm{OL}, \mathrm{EMI}}$ é a radiação de onda longa emitida pela superfície $\left(\mathrm{W} \mathrm{m}^{-2}\right), \varepsilon_{\mathrm{o}}$ é a emissividade de cada pixel que representa a superfície terrestre e $\alpha$ o albedo.

Foram considerados três procedimentos distintos quanto à radiação de onda curta incidente, radiação de onda longa incidente e emissividade de cada pixel. Para diferenciação de cada critério definiu-se a seguinte convenção: saldo de radiação
Allen - RnA, saldo de radiação Zillman - RnZ e saldo de radiação com medições locais de radiação solar - RnE, cujas equações são detalhadas na Tabela 1 .

Em todos os três procedimentos o albedo foi estimado por meio da seguinte expressão (Di Long et al., 2010):

$$
\begin{aligned}
\alpha= & 0,215 \rho_{1}+0,215 \rho_{2}+0,242 \rho_{3}+0,129 \rho_{4}+0,101 \rho_{5} \\
& +0,062 \rho_{6}-0,036 \rho_{7}
\end{aligned}
$$

em que $\rho 1, \rho 2, \rho 3, \rho 4, \rho 5, \rho 6$ e $\rho 7$ são as refletâncias monocromáticas relativas a cada uma das sete bandas espectrais do MODIS, distribuídas por meio do produto MOD09GA.

Conforme Tabela 1 utilizaram-se os índices de vegetação IAF - Índice de Área Foliar e SAVI - Índice de Vegetação Ajustado aos Efeitos do Solo, no cálculo do RnE, mais especificamente no cálculo da emissividade de cada pixel.

Admite-se que as medidas do saldo de radiação são representativas de toda área da estação meteorológica experimental, pois a sua bordadura é suficientemente ampla para assegurar que o Rn se mantém em sua bordadura.

Considerou-se que a $\mathrm{R}_{\mathrm{OC}, \mathrm{INC}}$ e $\mathrm{R}_{\mathrm{OL} \_\mathrm{ATM}}$ se mantinham constantes sobre toda a bacia hidrográfica no instante da passagem do Terra/Aqua sobre a área de estudo. Já o saldo de radiação diário $\left(\mathrm{W} \mathrm{m}^{-2}\right)$ foi estimado segundo expressão (De Bruin e Stricker, 2000), que apresenta a vantagem de ponderar a $\mathrm{Rn}_{24 \mathrm{~h} \text { est }}$ por meio da radiação solar global diária medida, o que contempla a ocorrência de nuvens fora do instante da passagem do Terra/Aqua, diferentemente do modelo proposto por Bisht et al. (2005) que é válido apenas para dia com ausência de nuvens em todo o dia:

$$
R n_{24 h_{-} e s t}=(1-\alpha) R_{O C, 24 h_{-} \text {med }}-110 \tau_{24 h}
$$

em que $\alpha$ é o albedo da superfície, estimado com base nas refletâncias do produto MOD09GA (Equação 2); $\mathrm{R}_{\mathrm{oc}, 24 \mathrm{~h} \_ \text {med }}$ é a radiação solar global média diária medida na estação $\left(\bar{W}^{-2}\right)$ e $\tau_{24 \mathrm{~h}}$ transmissividade atmosférica diária, obtida por:

$$
\tau_{24 h}=\frac{R_{O C, 24 h \_m e d}}{R_{\text {TOA_24h }}}
$$

em que $\mathrm{R}_{\mathrm{TOA} \_24 \mathrm{~h}}$ é a radiação solar diária incidente no topo da atmosfera $\left(\mathrm{W} \mathrm{m}^{-2}\right)$.

O saldo de radiação num dado ponto, ou local de pequena dimensão, depende fundamentalmente das diferentes componentes do Balanço de Radiação (radiação solar, radiação atmosférica, temperatura da superfície, etc), mas uma vez conhecido o seu albedo, pode-se estimar o $\mathrm{Rn}_{24 \mathrm{~h} \text { est }}$ com boa precisão (Equação 3). A grande vantagem é que com o albedo por sensoriamento remoto e a transmissividade atmosférica diária $\left(\tau_{24 h}\right)$, se pode projetar o $\mathrm{Rn}_{24 \mathrm{~h} \text { est }}$. De outro modo, terse-ia que usar medidas de Rn em cada pixel, ou área com as mesmas características biofísicas (albedo, NDVI, temperatura 
Tabela 1 - Resumo das equações utilizadas no Saldo de radiação Allen (RnA), Saldo de radiação Zillman (RnZ) e Saldo de radiação com medições locais da radiação solar (RnE)

$\mathrm{R}_{O C, I N C}=\frac{S \operatorname{RnA}}{d^{2}}$
$d^{2}=\frac{1}{1+0,033 \cos \left(\frac{D S A 2 \pi}{365}\right)}$

$\mathrm{S}$ é a constante solar $\left(1.367 \mathrm{~W} \mathrm{~m}^{-2}\right)$; $\mathrm{Z}$ ângulo zenital solar (graus), obtido no produto MOD09GA; $\mathrm{d}^{2}$ quadrado da distância relativa Terra-Sol; $\tau$ transmissividade atmosférica no domínio da radiação solar (Allen et al., 2007); DSA é o dia sequencial do ano

$$
\tau=0,35+0,627 \exp \left[\frac{-0,00146 P}{K_{t} \cos Z}-0,075\left(\frac{W}{\cos Z}\right)^{0,4}\right] \quad W=0,14 e_{a} P+2,10
$$

Kt é o coeficiente de turbidez da atmosfera $(\mathrm{Kt}=1$, para céu claro e limpo); P pressão atmosférica $(\mathrm{kPa})$ e W água precipitável (mm). (Oliveira et al., 2012; Garrison e Adler, 1990):

$$
P=101,3\left(\frac{T_{a}-0,0065 h}{T_{a}}\right)^{5,26} \quad e_{a}=\frac{U R e_{S}}{100} \quad e_{S}=0,61078 \exp ^{\left[\frac{17,269 T_{a r}}{\left(237,3+T_{a r}\right)}\right]}
$$

$T_{a}$ é a temperatura do ar (K); h (m) altitude da área; e pressão atual de vapor de água (kPa); UR (\%) umidade relativa do ar medida na estação meteorológica experimental e $\mathrm{e}_{\mathrm{s}}$ é a pressão de saturação à temperatura do ar (kPa). Tanto a temperatura do ar $\left(\mathrm{T}_{\mathrm{a}}\right)$ como a umidade relativa do ar (UR) foram monitorados na estação meteorológica experimental.

$$
\mathrm{R}_{O L_{-} A T M}=\varepsilon_{\mathrm{a}} \sigma \mathrm{T}_{\mathrm{a}}^{4} \quad \varepsilon_{\mathrm{a}}=0,85\left(-\ln \tau_{\mathrm{sw}}\right)^{0,09}
$$

$\varepsilon_{\mathrm{a}}$ é a emissividade atmosférica; $\sigma$ constante de Stefan-Boltzmann $\left(5,67 \times 10^{-8} \mathrm{Wm}^{-2} \mathrm{~K}^{-4}\right)$ (Bastiaanssen et al., 2005)

$\mathrm{R}_{O L_{-} E M I}=\varepsilon_{0} \sigma \mathrm{T}_{\text {sup }}{ }^{4} \quad \varepsilon_{0}=0,273+1,778 \varepsilon_{31}-1,807 \varepsilon_{31} \varepsilon_{32}-1,037 \varepsilon_{32}+1,774 \varepsilon_{32}{ }^{2}$

$\mathrm{T}_{\text {sup }}$ é a temperatura da superfície (K) obtida no produto MOD11A1; $\varepsilon_{0}$ emissividade de cada pixel (adimensional); $\varepsilon_{31}$ e $\varepsilon_{32}$ emissividades superficiais das bandas 31 e 32 do produto MOD11A1 (Di Long et al., 2010)

$\frac{\operatorname{RnZ}}{R_{O C, I N C}=\frac{S \cos ^{2} Z}{1,085 \cos Z+e_{a}(2,7+\cos Z) 10^{-3}+\beta} \quad e_{a}=\frac{U R e_{S}}{100} \quad e_{S}=0,61078 \exp ^{\left[\frac{17,269 T_{a r}}{\left(237,3+T_{a r}\right)}\right]}}$

$\beta=$ coeficiente de ajuste $(0,1)$ Zillman (1972)

$$
\begin{aligned}
& \mathrm{R}_{O L_{-} A T M}=\varepsilon_{\mathrm{a}} \sigma \mathrm{T}_{\mathrm{a}}^{4} \\
& \text { Prata (1996) }
\end{aligned} \quad \varepsilon_{\mathrm{a}}=1-(1+\xi) \exp \left\{-(1,20+3 \xi)^{1 / 2}\right\} \xi=\frac{46,5 e_{a}}{T_{a}}
$$

$\xi$ é a razão entre pressão atual de vapor de água e a temperatura do ar

$$
\mathrm{R}_{O L_{-} E M I}=\varepsilon_{0} \sigma \mathrm{T}_{\text {sup }}{ }^{4} \quad \varepsilon_{0}=0,273+1,778 \varepsilon_{31}-1,807 \varepsilon_{31} \varepsilon_{32}-1,037 \varepsilon_{32}+1,774 \varepsilon_{32}{ }^{2}
$$

$\varepsilon_{\mathrm{o}}$ é a emissividade de cada pixel (adimensional); $\varepsilon_{31}$ e $\varepsilon_{32}$ emissividades superficiais das bandas 31 e 32 do produto MOD11A1

\section{$\mathrm{RnE}$}

\begin{tabular}{lc}
\hline$R_{O C, I N C}=$ medida na estação meteorológica experimental \\
\hline $\mathrm{R}_{O L_{-} A T M}=\varepsilon_{\mathrm{a}} \sigma \mathrm{T}_{\mathrm{a}}{ }^{4}$ & $\varepsilon_{\mathrm{a}}=1-(1+\xi) \exp \left\{-(1,20+3 \xi)^{1 / 2}\right\} \quad \xi=\frac{46,5 e_{a}}{T_{a}}$ \\
\hline $\mathrm{R}_{O L_{-} E M I}=\varepsilon_{0} \sigma \mathrm{T}_{\text {sup }}{ }^{4}$ & $\varepsilon_{0}=0,95+0,01 I A F$
\end{tabular}

$\varepsilon_{\mathrm{o}}$ é a emissividade de cada pixel (adimensional) e IAF Índice de Área Foliar (adimensional)

$$
I A F=-\frac{\ln \left(\frac{0,69-S A V I}{0,59}\right)}{0,91} \quad S A V I=\frac{(1+L)\left(\rho_{b 2}-\rho_{b 1}\right)}{\left(L+\rho_{b 2}+\rho_{b 1}\right)}
$$

IAF é o Índice de Área Foliar (adimensional); pixels com IAF $\geq 3, \varepsilon_{\mathrm{o}}=0,98$ e corpos de água $(\mathrm{SAVI}<0,1), \varepsilon_{\mathrm{o}}=0,985$ (Allen et al., 2007); SAVI é o Índice de Vegetação Ajustado aos Efeitos do Solo (Huete, 1988), calculado pelas bandas do infravermelho próximo - $\rho$-ivp e do vermelho - $\rho$-ver do produto MOD09GA - camadas 2 e 3. 
da superfície, etc) o que seria inconcebível. Ressalta-se ainda que um dos dados de sensoriamento remoto considerado mais importante nos estudos de clima do nosso planeta é justamente o albedo.

As variáveis monitoradas na estação meteorológica experimental não são coincidentes com a hora de passagem dos satélites Terra e Aqua na área de estudo e, consequentemente, não representam a realidade da condição meteorológica naquele exato momento, ou seja, as variáveis medidas na estação são médias de cada 30 minutos e do produto MODIS representa um valor instantâneo. Nesse sentido, promoveu-se interpolação linear das variáveis monitoradas a cada 30 minutos para o instante da passagem do satélite sobre a área de estudo, de modo a possibilitar a comparação com o Rn instantâneo estimado pelos produtos MODIS. No entanto, deve-se considerar que seria natural haver discrepâncias entre o Rn medido em 30 minutos na estação e o Rn estimado pelos produtos MODIS, particularmente em áreas com grande intermitência de nuvens.

Para análise comparativa entre o saldo de radiação estimado segundo os três diferentes procedimentos com o Rn medido, utilizou-se a Diferença Absoluta Média-DAM (W $\mathrm{m}^{-2}$ ), Diferença Relativa Média-DRM (\%) e a Raiz da Diferença Quadrática Média-RDQM $\left(\mathrm{W} \mathrm{m}^{-2}\right)$ :

$$
\begin{aligned}
& \text { DAM }=\frac{1}{N} \sum_{i=1}^{N}\left|X_{\text {est }}-X_{\text {med }}\right| \\
& D R M=\frac{100}{N} \sum_{i=1}^{N}\left|\frac{X_{\text {est }}-X_{\text {med }}}{X_{\text {med }}}\right|
\end{aligned}
$$

$$
\mathrm{RDQM}=\left(\frac{\sum_{\mathrm{i}=1}^{\mathrm{N}}\left(\mathrm{X}_{\mathrm{est}}-\mathrm{X}_{\mathrm{med}}\right)^{2}}{\mathrm{~N}}\right)^{1 / 2}
$$

em que $\mathrm{X}_{\text {est }}$ é o valor do saldo de radiação instantâneo e/ou diário pelos diferentes procedimentos e $\mathrm{X}_{\text {med }}$ é o valor do saldo de radiação medido, com $\mathrm{N}$ igual ao número de pares das variáveis.

\section{RESULTADOS E DISCUSSÃO}

Na Figura 1 está representada a precipitação total mensal ( $\left.\mathrm{mm} \mathrm{mês}{ }^{-1}\right)$, as temperaturas e umidades relativas do ar médias mensais mínimas, médias e máximas do período de janeiro/2010 até agosto/2011. Observa-se que o período mensal de maior incidência pluviométrica foi entre abril e julho, sendo o ano de 2010 normal e 2011 chuvoso. A temperatura média mensal do ar variou de 23 a $27^{\circ} \mathrm{C}$ e a umidade média mensal do ar variou de 71 a $81 \%$.

A Tabela 2 apresenta os valores das variáveis complementares (medidas pelos sensores na estação experimental meteorológica) interpoladas linearmente e, consequentemente, consideradas como condição local no momento de passagem do satélite.

Procurou-se mostrar na Figura 2 as correlações entre RnA, RnZ e RnE com relação ao saldo medido pelo sensor NR-LITE da estação instalada na área de estudo.

Observou-se que o saldo de radiação com medições locais de radiação solar - RnE obteve melhor ajuste em

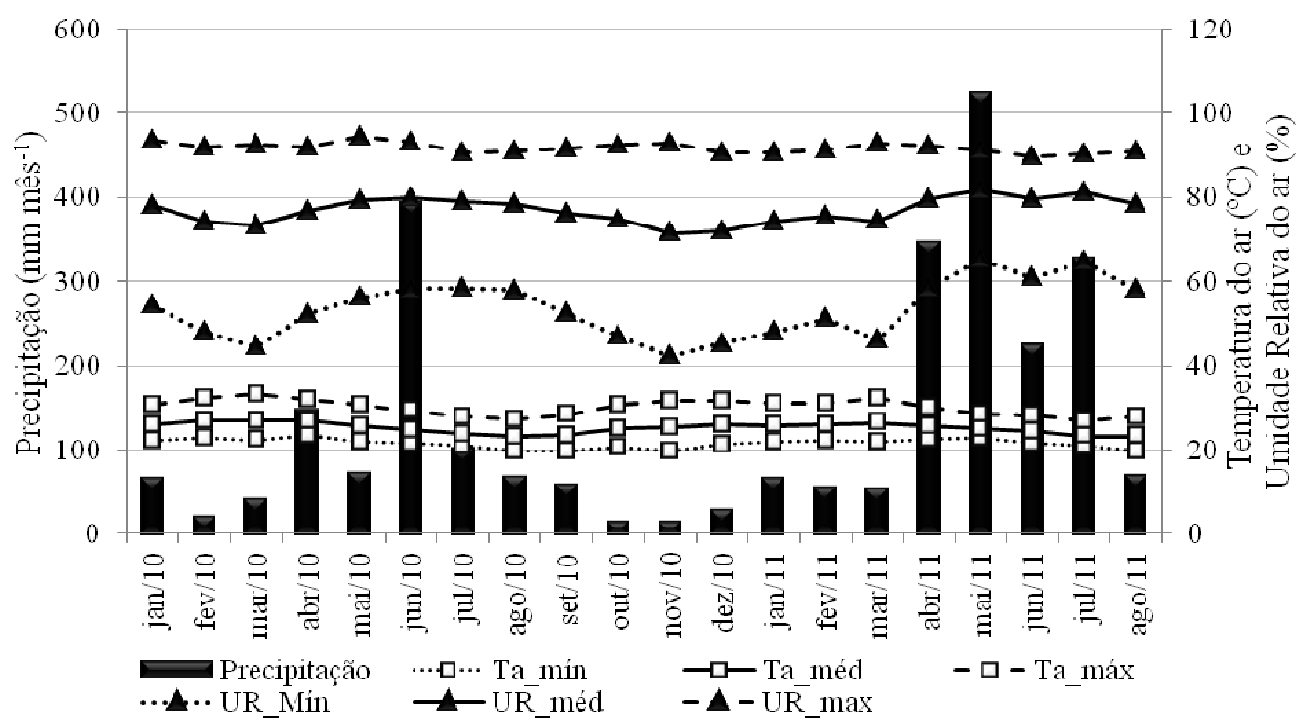

Figura 1 - Precipitação total mensal $\left(\mathrm{mm} \mathrm{mês}^{-1}\right)$; temperatura do ar média mensal mínima (Ta_mín); temperatura do ar média mensal (Ta_méd); temperatura do ar média mensal máxima (Ta_máx); umidade relativa do ar média mensal mínima (UR_mín); umidade relativa do ar média mensal (UR_méd) e umidade relativa do ar média mensal máxima (UR_máx). 
Tabela 2 - Dia Sequencial do Ano (DSA); Ângulo Zenital Solar - Z (graus); data dos produtos MODIS e variáveis interpoladas linearmente para o instante da passagem do satélite na estação meteorológica experimental: temperatura do ar - Ta $\left({ }^{\circ} \mathrm{C}\right)$, umidade relativa - UR (\%), radiação global $-\mathrm{Rg}\left(\mathrm{W} \mathrm{m} \mathrm{m}^{-2}\right)$ e saldo de radiação- $\mathrm{Rn}\left(\mathrm{W} \mathrm{m}^{-2}\right)$.

\begin{tabular}{|c|c|c|c|c|c|c|c|c|}
\hline \multirow{2}{*}{ DSA } & \multirow{2}{*}{$\begin{array}{c}\mathrm{Z} \\
\text { (graus) }\end{array}$} & \multirow{2}{*}{$\begin{array}{l}\text { Data dos } \\
\text { produtos } \\
\text { MODIS }\end{array}$} & \multirow{2}{*}{ Satélite } & \multicolumn{5}{|c|}{$\begin{array}{l}\text { Interpolação linear dos valores medidos a } \\
\text { cada } 30 \text { minutos }\end{array}$} \\
\hline & & & & $\begin{array}{c}\text { Hora } \\
(h)\end{array}$ & $\begin{array}{l}\mathrm{Ta} \\
\left({ }^{\circ} \mathrm{C}\right)\end{array}$ & $\begin{array}{l}\text { UR } \\
(\%)\end{array}$ & $\begin{array}{c}\mathrm{Rg} \\
\left(\mathrm{W} \mathrm{m}^{-2}\right)\end{array}$ & $\begin{array}{c}\mathrm{Rn} \\
\left(\mathrm{W} \mathrm{m}^{-2}\right)\end{array}$ \\
\hline 069 & 32,3 & $10 / 03 / 2010$ & Terra/MOD & $10: 00$ & 32,9 & 31,9 & 870,5 & 584,7 \\
\hline 120 & 31,3 & $30 / 04 / 2010$ & Terra/MOD & $10: 30$ & 30,9 & 52,7 & 820,5 & 609,1 \\
\hline 127 & 34,4 & $07 / 05 / 2010$ & Aqua/MYD & $13: 30$ & 31,0 & 50,6 & 636,9 & 436,9 \\
\hline 184 & 36,8 & 03/07/2010 & Aqua/MYD & $13: 24$ & 28,8 & 44,4 & 654,1 & 437,6 \\
\hline 227 & 35,4 & $15 / 08 / 2010$ & Terra/MOD & $10: 12$ & 27,6 & 61,0 & 776,6 & 558,4 \\
\hline 246 & 28,8 & 03/09/2010 & Aqua/MYD & $13: 36$ & 28,6 & 43,7 & 734,2 & 493,6 \\
\hline 076 & 30,5 & $17 / 03 / 2011$ & Aqua/MYD & $14: 06$ & 34,3 & 36,8 & 699,8 & 487,8 \\
\hline 096 & 29,0 & $06 / 04 / 2011$ & Aqua/MYD & $13: 42$ & 33,0 & 37,5 & 643,0 & 446,5 \\
\hline 112 & 32,9 & $22 / 04 / 2011$ & Aqua/MYD & $13: 42$ & 29,9 & 61,1 & 576,4 & 441,3 \\
\hline 133 & 40,6 & $13 / 05 / 2011$ & Aqua/MYD & $14: 00$ & 29,8 & 55,3 & 398,6 & 285,3 \\
\hline 151 & 40,7 & $31 / 05 / 2011$ & Aqua/MYD & $13: 48$ & 28,3 & 66,7 & 506,1 & 382,2 \\
\hline 171 & 37,4 & $20 / 06 / 2011$ & Aqua/MYD & $13: 24$ & 28,9 & 57,3 & 540,5 & 429,0 \\
\hline
\end{tabular}

(a)

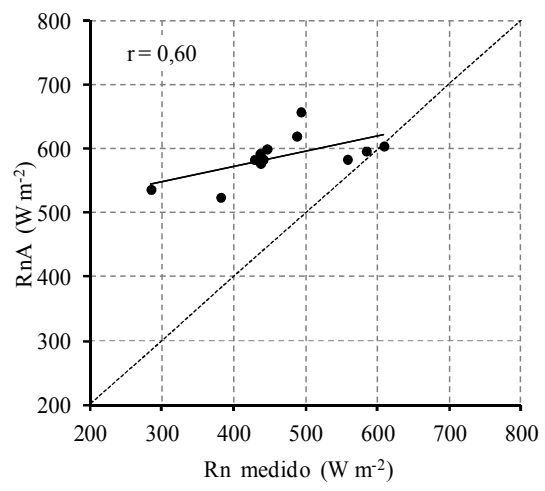

(b)

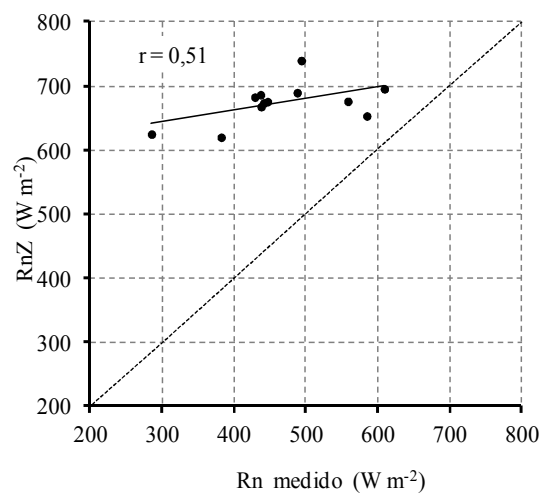

(c)

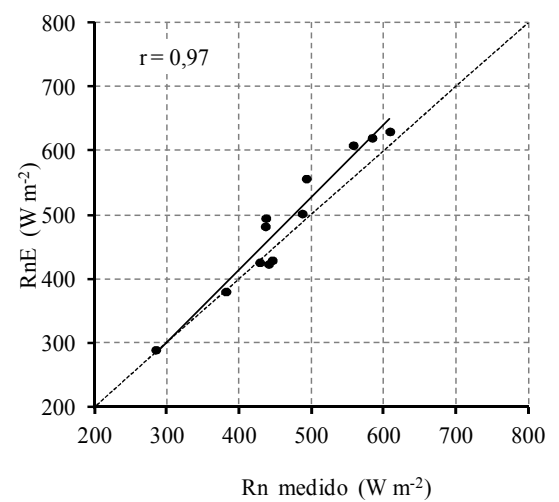

Figura 2 - Comparação entre o (a) Saldo de radiação Allen - RnA, (b) Saldo de radiação Zillman - RnZ e (c) Saldo de radiação com índices locais de radiação solar - RnE (C) com relação ao saldo medido na bacia do rio Tapacurá - PE.

relação ao saldo medido com coeficiente de correlação $(r=$ 0,97 ), aparentemente levando a considerar como sendo o procedimento mais indicado. Ademais, ao se utilizar a radiação solar global medida, os dados de RnE estimado pelos produtos MODIS, naturalmente, ajustam-se melhor aos medidos, em consequência da presença intermitente de nuvens na área de estudo, como se depreende na Figura 3, que representa a radiação solar global média medida a cada 30 minutos para os dias selecionados nesta pesquisa. Desta forma, o procedimento de cálculo do saldo de radiação instantâneo Allen - RnA (W $\mathrm{m}^{-2}$ ) representa, mais fidedignamente o saldo instantâneo na bacia do rio Tapacurá $-\mathrm{PE}$.

Este resultado condiz com Ruhoff et al. (2012) quando utilizaram produtos MODIS em áreas de cana-de-açúcar e cerrado, na bacia do Rio Grande. Os autores obtiveram para cana-de-açúcar $\mathrm{r}=0,94$ e para cerrado $\mathrm{r}=0,91$, quando compararam o Rn utilizando produtos MODIS com o $\mathrm{Rn}$ medido, mas destaca-se que nesse estudo foi empregado outro método de obtenção de Rn diário (proposto por Bisht et al., 2005, mas que somente se aplica a dias absolutamente sem 
presença de nuvens, o que não é o caso da área contemplada na presente pesquisa).

$\mathrm{Na}$ análise comparativa entre o RnA, RnZ e RnE com o saldo de radiação medido na estação experimental meteorológica resultou, respectivamente, em: Diferença Absoluta Média-DAM, de 122,4; 207,7 e 27,9 W m²; Diferença Relativa Média-DRM de 30,1; 49,4 e 5,7\% e; Raiz da Diferença Quadrática Média-RDQM de 140,7; 220,8 e $35,1 \mathrm{~W} \mathrm{~m}^{-2}$.

Observa-se que o RnE apresentou as menores diferenças analisadas de DAM, DRM e RDQM $\left(27,9 \mathrm{~W} \mathrm{~m}^{-2} ; 5,7 \%\right.$ e 35,1
$\mathrm{W} \mathrm{m}^{-2}$ ), o que era de se esperar em virtude dos problemas provocados pela presença de nuvens nas medidas semi-horárias. A DRM condiz com o estudo de Santos (2011) que obteve DRM de 7,1\% em cerrado e de 9,4\% em cana-de-açúcar quando comparou a $\mathrm{Rn}$ estimado por produtos MODIS e com o Rn medido.

O saldo de radiação instantâneo estimado pelos produtos MODIS variou de 380 a $720 \mathrm{~W} \mathrm{~m}^{-2}$ e pode-se constatar que o $\mathrm{Rn}$ recebeu forte influência do albedo e a temperatura da superfície, não obstante os seus valores finais guardarem forte dependência da radiação solar instantânea (Figura 4).
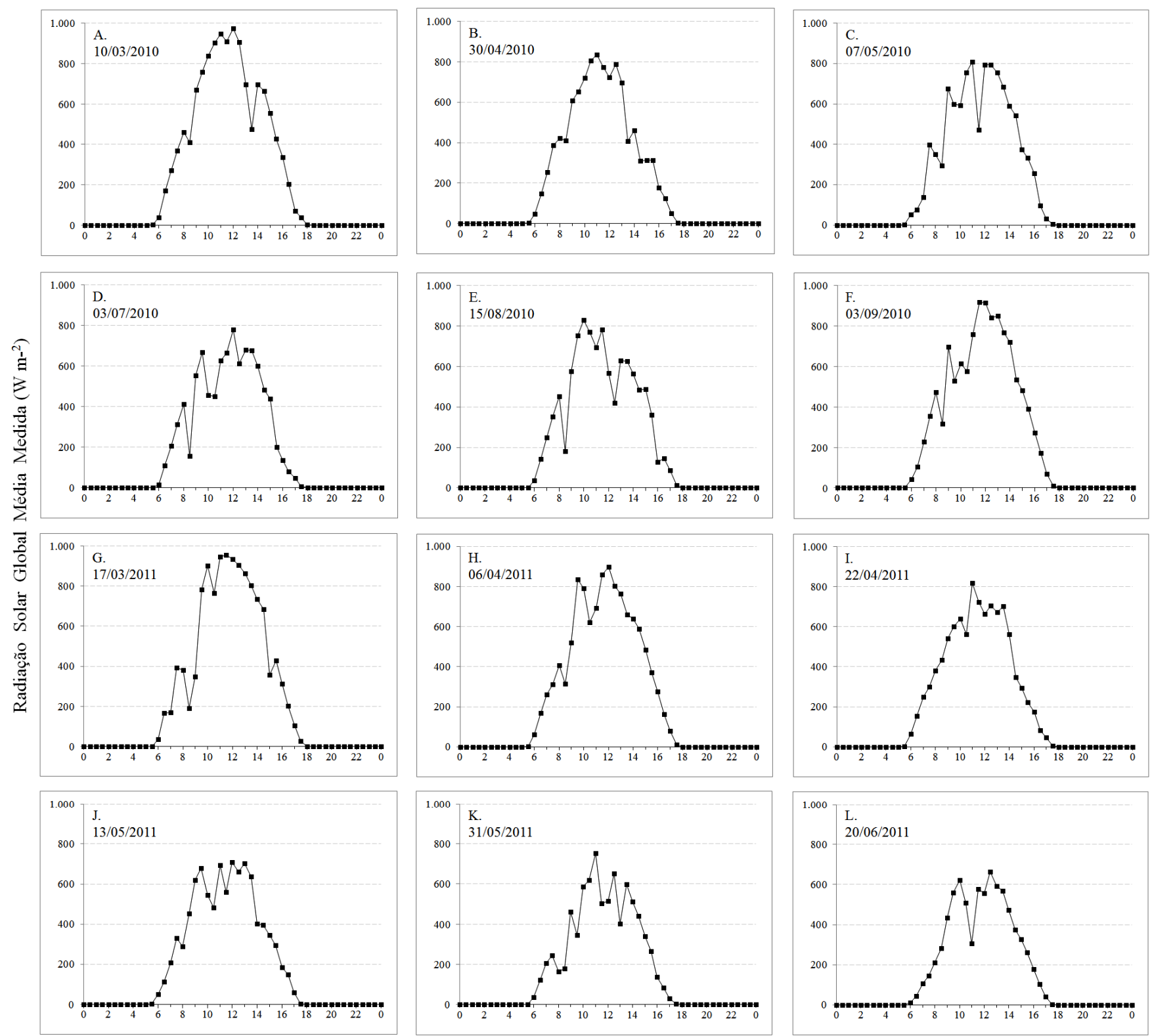

Hora Local

Figura 3 - Radiação solar global média medida a cada 30 minutos na bacia do rio Tapacurá - PE. 
Observa-se que em algumas áreas das cenas estudadas, ilustradas na Figura 4A (10/03/2010) e Figura 4F (03/09/2010), que o Rn apresentou menor magnitude em áreas urbanas (cidades de Vitória de Santo Antão e Pombos, com áreas respectivas de $371 \mathrm{~km}^{2}$ e $207 \mathrm{~km}^{2}$ ) ou solo exposto e, maior magnitude em áreas vegetadas e corpos hídricos. Estes resultados estão em concordância com os estudos realizados por Di Pace et al.
(2008) e Silva et al. (2005a), que constataram maior saldo de radiação em áreas vegetadas, em comparação com as áreas urbanas e solo exposto.

Observa-se na Figura 5 a configuração da cobertura terrestre da bacia do rio Tapacurá - $\mathrm{PE}$, em especial destaque as áreas urbanas de Vitória de Santo Antão e Pombos, também localizadas na Figura 4. Destaca-se ainda reservatório do
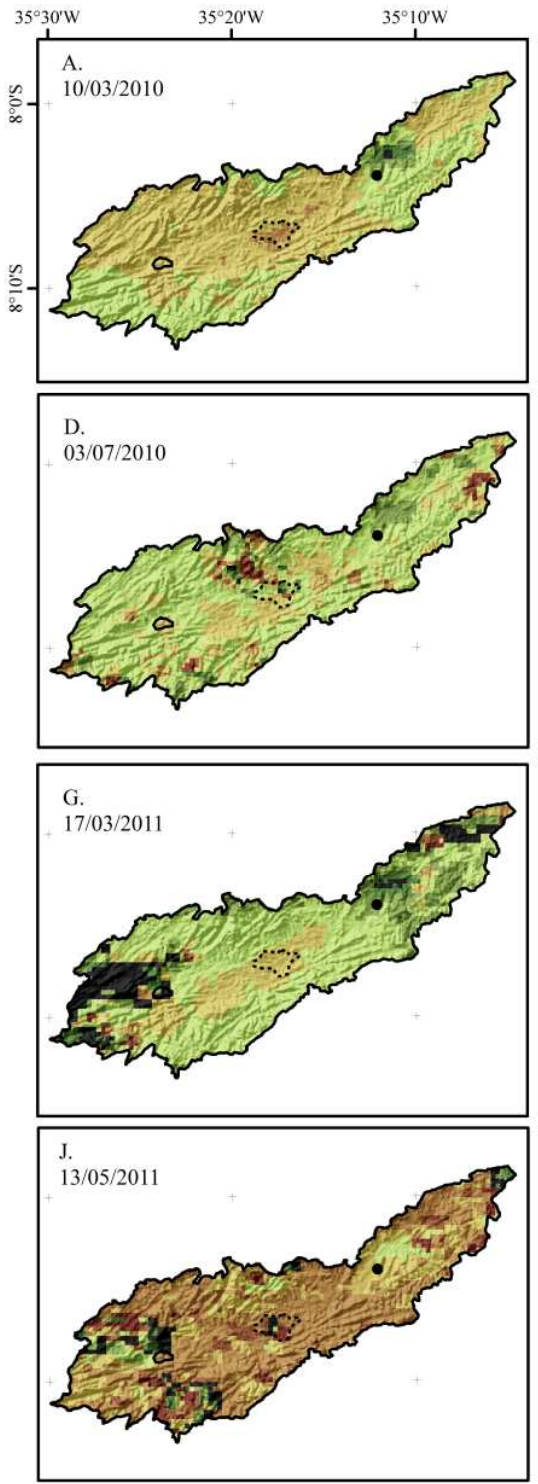

Saldo de Radiação Instantâneo Allen $\left(\mathrm{W} \mathrm{m}^{-2}\right)$

\begin{tabular}{|l|l|}
$\square<400$ & $\square 50-600$ \\
$400-450$ & $\square$ \\
$400-650$ \\
$450-500$ & \\
$500-550$ & $650-700$ \\
$500-500$
\end{tabular}
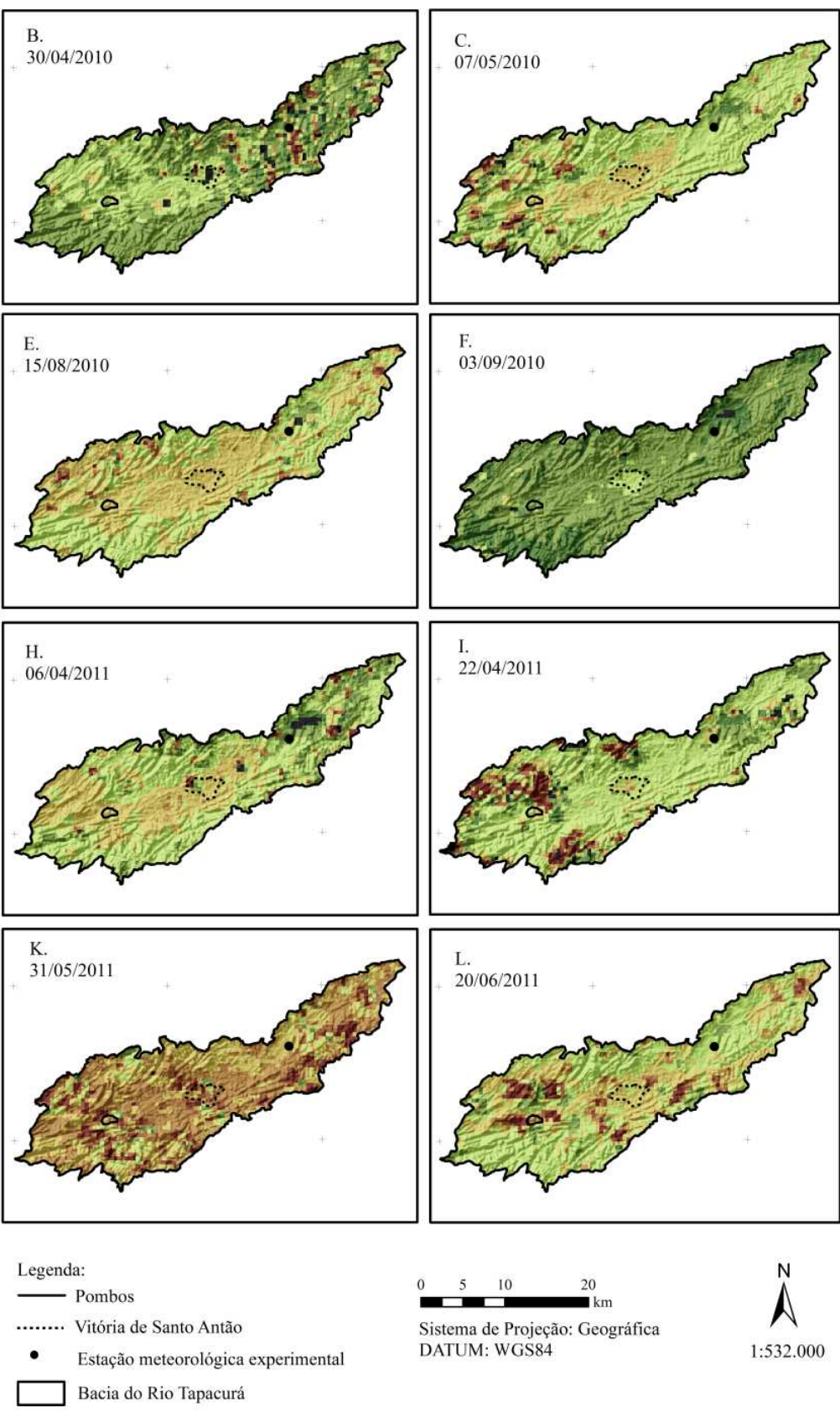

Figura 4 - Saldo de radiação instantâneo Allen - RnA ( $\mathrm{W} \mathrm{m}^{-2}$ ) estimado com produtos MODIS na bacia do rio Tapacurá - PE em: 10/03/2010 (A); 30/04/2010 (B); 07/05/2010 (C); 03/07/2010 (D); 15/08/2010 (E); 03/09/2010 (F); 17/03/2011 (G); 06/04/2011 (H); 22/04/2011 (I); 13/05/2011 (J); 31/05/2011 (k) e 20/06/2011 (L). 


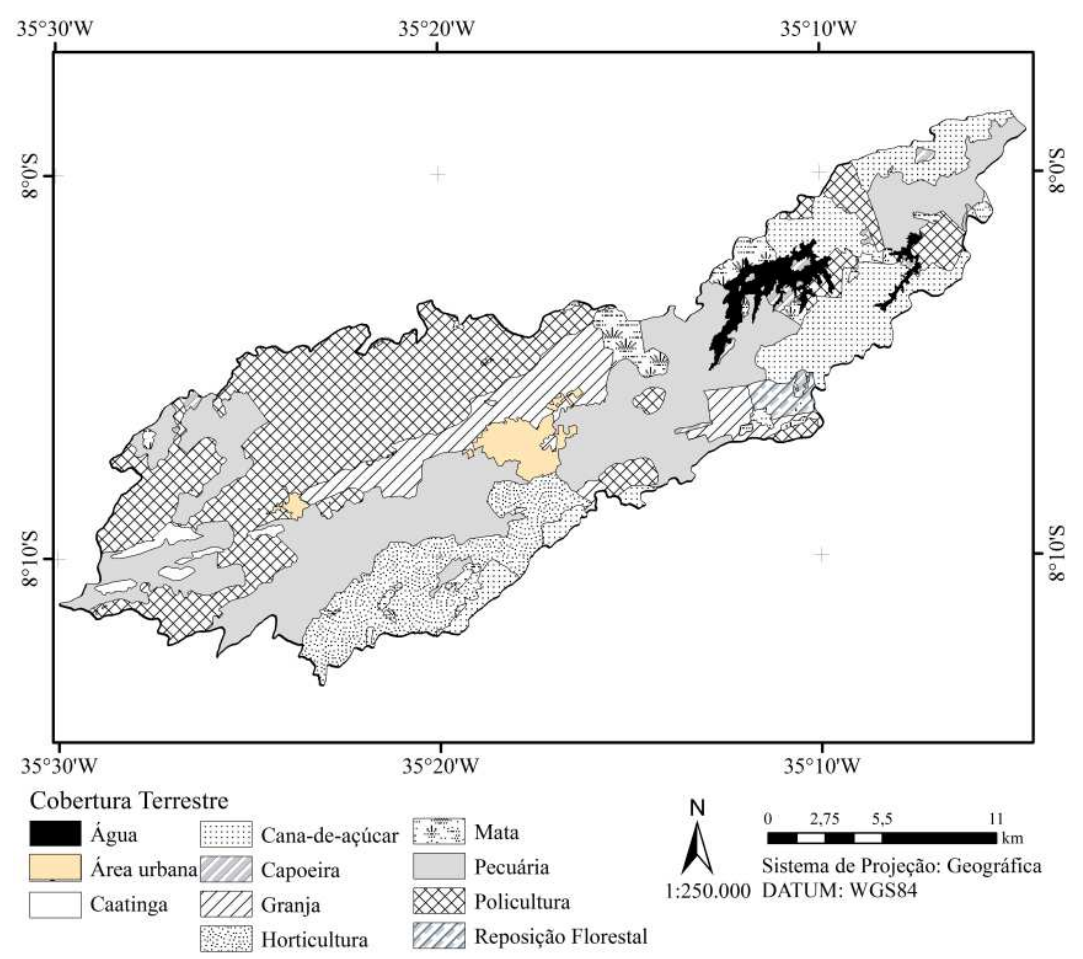

Figura 5 - Cobertura terrestre da bacia do rio Tapacurá - PE. Fonte: adaptado de Braga (2001).

Tapacurá e a área de pecuária (Figura 5) da localização da estação meteorológica experimental com cobertura em capimlucas (Sporobulus Indicus).

Ao se observar toda a cena estudada se constata que os maiores valores do saldo de radiação $\left(\mathrm{Rn}>650 \mathrm{~W} \mathrm{~m}^{-2}\right)$ encontram-se no reservatório do Tapacurá (Figura 4A, 4E), resultantes dos baixos valores do albedo e da temperatura da superfície nesse reservatório. Este comportamento com relação aos maiores valores de $\mathrm{Rn}$ em corpos hídricos foi similar aos resultados obtidos por Lima et al. (2012) em estudo com imagens MODIS, especificamente sobre parte do rio Preto e do ribeirão Entre Ribeiros e São Pedro. Estes autores obtiveram em corpos hídricos em 13/08/2007, 651<Rn $<750 \mathrm{~W} \mathrm{~m}^{-2}$ e em $14 / 07 / 2007,551<\mathrm{Rn}<650 \mathrm{~W} \mathrm{~m}^{-2}$.

Recentes pesquisas com o sensor MODIS comprovam que os valores obtidos com suas imagens são consistentes e compatíveis com resultados medidos em superfície, como a pesquisa de Santos (2011), que obteve Rn variando de 522,2 a $754,4 \mathrm{~W} \mathrm{~m}^{-2}$ em cerrado e de 495,1 a $736,5 \mathrm{~W} \mathrm{~m}^{-2}$ em canade-açúcar, com erro percentual médio inferior a $10 \%$. Esse autor enfatizou que o clima da região foi impactado quando da substituição da vegetação nativa por cana-de-açúcar, onde tal substituição ocasionou uma diminuição do Rn e um aumento na temperatura da superfície. Também com sensor MODIS, Lima et al. (2012) obtiveram valores mínimo, médio e máximo respectivamente iguais a 447,40; 575,38 e 731,14 $\mathrm{W} \mathrm{m}{ }^{-2}$. Estes autores enfatizaram que informações orbitais podem auxiliar a determinação do Rn em áreas onde não existem estações meteorológicas automáticas que registrem o saldo de radiação.

Ataíde et al. (2006) obtiveram o saldo de radiação com produtos MODIS para o dia 25/10/2005 e compararam os resultados obtidos a partir dos satélites Terra e Aqua com os dados medidos em estação meteorológica experimental na fazenda Frutacor no município de Quixeré no Ceará. Nesse estudo os autores utilizaram cartas georreferenciadas do sensor MODIS com dados de albedo, temperatura da superfície, emissividades, temperatura do ar e do ponto de orvalho, e obtiveram valores de $\mathrm{Rn}$ igual a $771,7 \mathrm{~W} \mathrm{~m}^{-2}$ quando na utilização dos dados do satélite Terra, com percentual de concordância de 94,70\% em relação aos valores medidos. Quando utilizaram os dados do satélite Aqua, o Rn obtido foi de 764,5 $\mathrm{W} \mathrm{m}^{-2}$ com percentual de concordância de $89,50 \%$.

A Tabela 3 resume os resultados dos valores da radiação solar diária incidente no topo da atmosfera - $\mathrm{R}_{\mathrm{TOA}}$ 24h $\left(\mathrm{W} \mathrm{m}^{-2}\right)$; radiação solar incidente média diária medida na estação meteorológica experimental $-\mathrm{R}_{\mathrm{OC}, 24 \mathrm{~h} \text { med }}\left(\mathrm{W} \mathrm{m}^{-2}\right)$; transmissividade atmosférica no domínio da radiação solar - $\tau_{24 \mathrm{~h}}$, bem como os resultados obtidos quando se comparou saldo de radiação diário $-\mathrm{Rn}_{24 \mathrm{~h} \_s t}\left(\mathrm{~W} \mathrm{~m}^{-2}\right)$ estimado pelos 
Tabela 3 - Data dos produtos MODIS; Albedo; Saldo de radiação instantâneo estimado - RnA (W m ${ }^{-2}$ ); Radiação solar diária incidente no topo da atmosfera - $\mathrm{R}_{\mathrm{TOA} \_24 \mathrm{~h}}\left(\mathrm{~W} \mathrm{~m}^{-2}\right)$; Radiação solar incidente média diária medida - $\mathrm{R}_{\mathrm{OC}, 24 \mathrm{~h} \text { med }}\left(\mathrm{W} \mathrm{m}^{-2}\right)$; Transmissividade atmosférica no domínio da radiação solar - $\tau_{24 h}$; Saldo de radiação diário estimado com produtos MODIS - $\mathrm{Rn}_{24 \mathrm{~h} \text { est }}\left(\mathrm{W} \mathrm{m}^{-2}\right)$; Saldo de radiação médio diário medido - $\mathrm{Rn}_{24 \mathrm{~h} \_ \text {med }}$ $\left(\mathrm{W} \mathrm{m} \mathrm{m}^{-2}\right)$; Diferença Relativa (\%) entre os saldo de radiação diário medido e estimado na bacia do rio Tapacurá - PE.

\begin{tabular}{|c|c|c|c|c|c|c|c|c|}
\hline \multirow{2}{*}{$\begin{array}{l}\text { Data dos } \\
\text { produtos } \\
\text { MODIS }\end{array}$} & \multirow{2}{*}{ Albedo } & \multirow{2}{*}{$\operatorname{RnA}\left(\mathrm{W} \mathrm{m}^{-2}\right)$} & \multicolumn{2}{|c|}{$\begin{array}{l}\text { Radiação incidente }\left(\mathrm{W} \mathrm{m}^{-2}\right) \\
\end{array}$} & & \multicolumn{2}{|c|}{ Rn diário $\left(\mathrm{W} \mathrm{m}^{-2}\right)$} & \multirow{2}{*}{ DR (\%) } \\
\hline & & & $\mathrm{R}_{\mathrm{TOA} \_4 \mathrm{~h}}$ & $\mathrm{R}_{\mathrm{OCC} 24 \_ \text {med }}$ & & $\mathrm{Rn}_{24 h_{\text {_est }}}$ & $\mathrm{Rn}_{24 \mathrm{~h} \_ \text {med }}$ & \\
\hline 10/03/2010 & 21,4 & 595,6 & 442,6 & 266,5 & 0,60 & 154,7 & 151,1 & 2,4 \\
\hline 30/04/2010 & 16,5 & 603,4 & 386,6 & 217,6 & 0,56 & 120,6 & 129,2 & 6,6 \\
\hline 07/05/2010 & 15,0 & 591,8 & 377,9 & 218,0 & 0,58 & 130,9 & 130,7 & 0,0 \\
\hline 03/07/2010 & 14,4 & 576,3 & 348,1 & 195,0 & 0,56 & 110,4 & 107,6 & 2,6 \\
\hline $15 / 08 / 2010$ & 17,0 & 582,8 & 386,6 & 215,7 & 0,56 & 123,7 & 117,3 & 5,4 \\
\hline 03/09/2010 & 14,7 & 656,8 & 409,9 & 242,5 & 0,59 & 148,0 & 139,6 & 6,0 \\
\hline $17 / 03 / 2011$ & 18,4 & 618,9 & 437,4 & 258,2 & 0,59 & 157,5 & 156,0 & 0,0 \\
\hline 06/04/2011 & 14,1 & 599,1 & 417,0 & 241,6 & 0,58 & 139,4 & 143,6 & 2,9 \\
\hline $22 / 04 / 2011$ & 14,7 & 582,7 & 396,9 & 207,3 & 0,52 & 115,8 & 140,3 & 17,5 \\
\hline 13/05/2011 & 15,7 & 535,8 & 370,8 & 194,3 & 0,52 & 111,7 & 126,3 & 11,5 \\
\hline $31 / 05 / 2011$ & 14,1 & 523,6 & 354,2 & 170,8 & 0,48 & 96,3 & 104,3 & 7,6 \\
\hline 20/06/2011 & 13,2 & 582,5 & 346,2 & 165,8 & 0,48 & 95,4 & 100,8 & 5,4 \\
\hline
\end{tabular}

produtos MODIS, com o saldo de radiação medido na estação meteorológica experimental $-\mathrm{Rn}_{24 \mathrm{~h} \text { med }}\left(\mathrm{W} \mathrm{m}^{-2}\right)$.

O saldo de radiação diário estimado por produtos MODIS - $\mathrm{Rn}_{24 \mathrm{~h} \_s t}\left(\mathrm{~W} \mathrm{~m}^{-2}\right)$ variou de 95,4 a $157,5 \mathrm{~W} \mathrm{~m}^{-2}$, com média de $125,4 \mathrm{~W} \mathrm{~m}^{-2}$ no local da estação meteorológica experimental. Com base nas estimativas pelos produtos MODIS e medições realizadas localmente, foram obtidas a Diferença Absoluta Média-DAM $\left(\mathrm{W} \mathrm{m}^{-2}\right)$, Diferença Relativa MédiaDRM (\%) e a Raiz da Diferença Quadrática Média-RDQM $\left(\mathrm{W} \mathrm{m}^{-2}\right.$ ), respectivamente iguais a $7,4 \mathrm{~W} \mathrm{~m}^{-2} ; 5,8 \%$ e $9,7 \mathrm{~W}$ $\mathrm{m}^{-2}$. Gusmão et al. (2012) obtiveram em suas pesquisas com TM Landsat 5 valores de DAM $\left(2,8 \mathrm{~W} \mathrm{~m}^{-2}\right)$, DRM $(1,9 \%) \mathrm{e}$ $\operatorname{RDQM~}\left(3,3 \mathrm{~W} \mathrm{~m}^{-2}\right)$, quando compararam a $\mathrm{Rn}_{24 \mathrm{~h}}$ medida e estimada por sensoriamento remoto em 2005 na Ilha do Bananal - TO. A resolução espacial interfere nos resultados dos estudos com sensoriamento remoto, pois nesta pesquisa foi utilizado o MODIS (Rn com resolução espacial de 463 m) e, o TM Landsat 5 apresenta resolução espacial de $30 \mathrm{~m}$. Bisht e Bras (2010), com produtos MODIS, obtiveram RDQM de $38 \mathrm{~W} \mathrm{~m}^{-2}$, elevado em relação a esta pesquisa e provavelmente em decorrência da suposição de Rn nulo em todo período noturno.

A transmissividade atmosférica média diária no domínio da radiação solar - $\tau_{24 h}$, variou de 0,48 a 0,60 (Tabela 3 ), enquanto que os valores da transmissividade atmosférica no domínio da radiação solar instantânea - $\tau$, variaram de 0,71 a 0,74 . Esses dados evidenciam a constante presença de nebulosidade, o que provoca grande dificuldade ao emprego de imagens orbitais, em particular no estudo do balanço radiativo. Não obstante as interferências da nebulosidade, as diferenças entre o Rn diário estimado e medido apresentaram boa concordância, corroborada com as baixas diferenças relativas $(7,6$ e $5,4 \%)$ e absolutas (8 e $5,4 \mathrm{~W} \mathrm{~m}^{-2}$ ) nos dias de menores valores da transmissividade atmosférica (31/05/2011 e 20/06/2011).

Ressalta-se ainda outro fator relevante, a influência do ângulo zenital do solar - Z (graus) que representa o ângulo formado entre a vertical local e o vetor posição do Sol no instante da passagem do satélite na área de estudo. Conforme a Tabela 3, o maior RnA (03/09/2010, $\left.\mathrm{RnA}=656,8 \mathrm{~W} \mathrm{~m}^{-2}\right)$ foi registrado o menor valor de $Z$ dentre os dias estudados, qual seja, $Z=28,8^{\circ}$ (Tabela 2). Entretanto, quando se observou o dia com menor $\operatorname{RnA}\left(31 / 05 / 2011, \mathrm{RnA}=523,6 \mathrm{~W} \mathrm{~m}^{-2}\right)$, o valor de $Z=40,7^{\circ}$ foi o maior detectado em todo o período estudado. Resultados semelhantes entre $\mathrm{Z}$ e Rn com produtos MODIS foram encontrados em Santos (2011) e Mendonça (2007), e Borges et al. (2010) com imagens TM- Landsat 5.

Silva et al. (2011), quando estudaram o balanço de radiação no perímetro irrigado de São Gonçalo na Paraíba mediante imagens orbitais do sensor TM Landsat 5, obtiveram o saldo de radiação em 24 horas $-\mathrm{Rn}_{24 \mathrm{~h}}$ para o ano de 2008 nas seguintes magnitudes em $\mathrm{MJ} \mathrm{m}^{-2}$ : área do açude São Gonçalo $\left(14,98<\mathrm{Rn}_{24 \mathrm{~h}}<16,99\right)$; pomar de bananeiras irrigado $\left(12,69<\mathrm{Rn}_{24 \mathrm{~h}}<14,23\right)$ e solo exposto $\left(8,26<\mathrm{Rn}_{24 \mathrm{~h}}<9,72\right)$. Já Andrade et al. (2012) em estudos no Bioma Pantanal que abrange os estados de Mato Grosso e Mato Grosso do Sul, com 


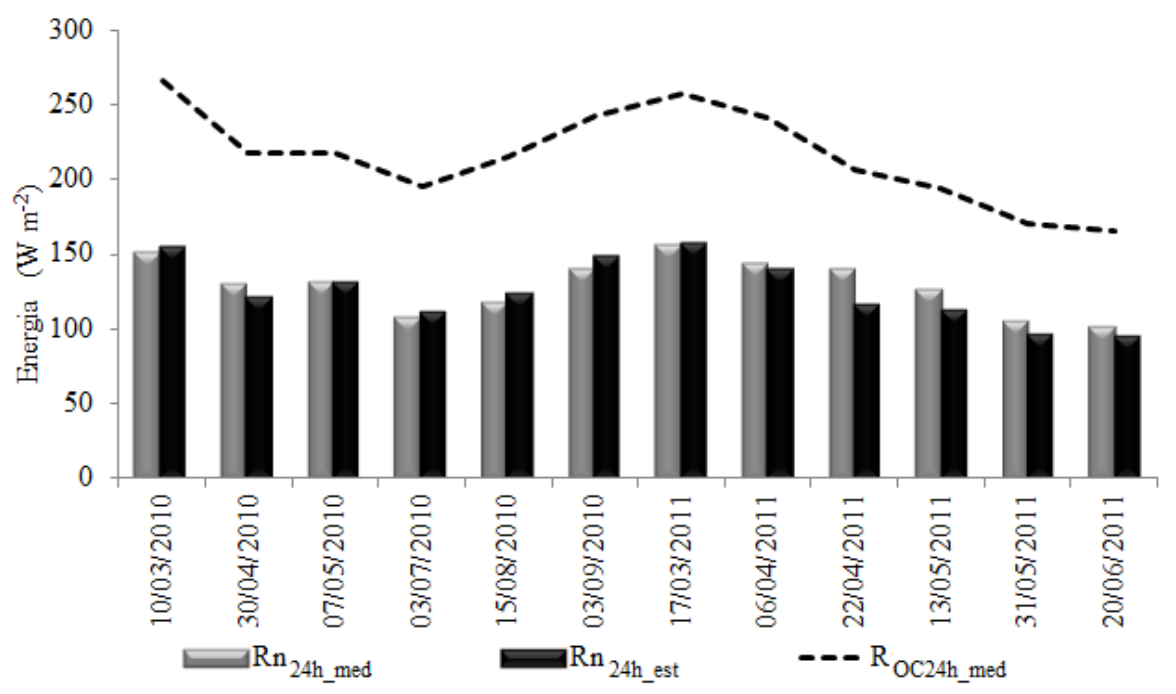

Figura 6 - Radiação solar incidente média diária medida na estação meteorológica experimental $\mathrm{R}_{\mathrm{OC} 24 \mathrm{~h} \text { med }}\left(\mathrm{W} \mathrm{m}^{-2}\right)$, saldo de radiação diário estimado pelos produtos MODIS $-\mathrm{Rn}_{24 \mathrm{~h} \text { est }}\left(\mathrm{W} \mathrm{m}^{-2}\right)$ e saldo de radiação medido na estação meteorológica experimental $-\mathrm{Rn}_{24 \mathrm{~h}}$ med $\left(\mathrm{W} \mathrm{m}^{-2}\right)$.

imagens MODIS / Terra do dia 11/08/2002, obtiveram resultados do saldo de radiação diário médio de $6,9 \mathrm{MJ} \mathrm{m}^{-2}$ para classes de uso do solo em pecuária, agricultura e outras áreas antrópicas. Estes mesmos autores também detectaram valores acima de $8,6 \mathrm{MJ} \mathrm{m}^{-2}$ em áreas muito úmidas, alagadas ou em superfície de corpos de água. Especificamente, a classe de água foi a que apresentou os maiores valores médios $\left(\mathrm{Rn}_{24 \mathrm{~h}}=11,4 \mathrm{MJ} \mathrm{m}^{-2}\right)$.

A partir da Figura 6 observa-se estreita relação entre a radiação solar incidente média diária medida na estação meteorológica experimental $-\mathrm{R}_{\mathrm{OC} 24 \mathrm{~h} \text { med }}\left(\mathrm{W} \mathrm{m}^{-2}\right)$ com o saldo de radiação diário estimado $-\mathrm{Rn}_{24 \mathrm{~h} \text { est }}\left(\mathrm{W} \mathrm{m}^{-2}\right)$ e saldo de radiação diário medido na estação meteorológica experimental - $\mathrm{Rn}_{24 \mathrm{~h} \text { med }}\left(\mathrm{W} \mathrm{m}^{-2}\right)$. Relação esta já esperada, pois o saldo de radiação contabiliza as radiações de ondas curta e longa e, depende fundamentalmente do fluxo de radiação solar que alcança a superfície terrestre.

Observa-se comportamento semelhante entre o saldo de radiação e a radiação incidente (Figura 6). Detectam-se pequenas diferenças entre o saldo de radiação diário medido e o saldo de radiação estimado pelos produtos MODIS comprovados pelas baixas diferenças relativas $(0,0<\mathrm{DR}<17,5 \%)$ registrados na Tabela 3.

\section{CONCLUSÕES}

O balanço de radiação à superfície por sensoriamento remoto, utilizando produtos MODIS, dados meteorológicos complementares e mesmo com a intensa presença de nebulosidade na bacia do rio Tapacurá - PE apresentou resultados compatíveis com outros estudos confirmando a eficiência na aplicabilidade da técnica.
As diferenças obtidas estão também em concordância com outros estudos, exceto aquela associada ao RnA instantâneo, que difere consideravelmente do Rn medido em 30 minutos. Não obstante as condições de tempo local, o Rn diário apresentou grande concordância com as medições do Rn medido na estação experimental, o que evidencia a importância da ponderação proporcionada pela radiação solar global diária.

\section{AGRADECIMENTOS}

Os autores agradecem ao Conselho Nacional de Desenvolvimento Científico e Tecnológico (CNPq), pela bolsa de Doutorado do primeiro autor, pelo apoio financeiro a esta pesquisa e pela bolsa de Produtividade e Pesquisa concedida aos segundo e terceiro autores; à Financiadora de Estudos e Projetos (FINEP) pelo apoio financeiro; à Rede de Hidrologia do Semiárido (REHISA); à Coordenação de Aperfeiçoamento de Pessoal de Nível Superior (CAPES) Brasil pela concessão de bolsa de pós-doutorado do primeiro autor e apoio financeiro; à Fundação de Amparo à Ciência e Tecnologia do Estado de Pernambuco (FACEPE) e à Agência Pernambucana de Águas e Clima (APAC) pela concessão de bolsa de pós-doutorado do primeiro autor.

\section{REFERÊNCIAS BIBLIOGRÁFICAS}

ALLEN, R. G.; TASUMI, M.; TREZZA, R. Satellite-based energy balance for mapping evapotranspiration with internalized calibration (METRIC) - Model. Journal of Irrigation and Drainage Engineering, v.133, n.4, p.380394, 2007. 
ANDERSON, L. O.; LAESTAÇÃO, M. L.; SHIMABUKURO, Y.E.; ARAI, E; JÚNIOR, O. A. DE C. Sensor MODIS: uma abordagem geral. INPE-10131-RPQ/752, São José dos Campos, São Paulo, Instituto Nacional de Pesquisas Espaciais (INPE), 58p., 2003.

ANDERSON, M. C.; ALLEN, R. G., MORSE, A.; KUSTAS, W. P. Use of Landsat thermal imagery in monitoring evapotranspiration and managing water resources. Remote Sensing of Environment, v.122, p.50-65, 2012.

ANDRADE, R. G.; SEDIYAMA, G. C.; PAZ, A. R. da; LIMA, E. de P.; FACCO, A. G. Geotecnologias aplicadas à avaliação de parâmetros biofísicos do Pantanal. Pesquisa Agropecuária Brasileira, v.47, n.9, p.1227-1234, 2012.

ARAÚJO, T. L.; DI PACE, F. T. Valores instantâneos da temperatura da superfície terrestre na Cidade de MaceióAL utilizando imagens do satélite TM/Landsat 5. Revista Brasileira de Geografia Física, v.3, p.104-111, 2010.

ATAÍDE, K. R. da P.; SILVA, B. B.da; CAVALVANTI, E. P. Resultados preliminares da estimativa do saldo de radiação diurno usando imagens do sensor MODIS (Terra/Aqua) para sai de céu claro. Revista Sodebrás, v.1, n.1, 2006.

BASTIAANSSEN, W. G. M.; NOORDMAN, E. J. M.; PELGRUM, H.; DAVIDS, G.; THORESON, B. P.; ALLEN, R.G. SEBAL model with remotely sensed data to improve water resources management under actual field conditions. Journal of Irrigation and Drainage Engineering, v.131, n.1, p.85-9, 2005.

BEZERRA, M. V. C.; SILVA, B. B.da; BEZERRA, B. G. Avaliação dos efeitos atmosféricos no albedo e NDVI obtidos com imagens de satélite. Revista Brasileira de Engenharia Agrícola e Ambiental, v. 15, n.7, p.709-717, 2011.

BISHT, G.; BRAS, R. L. Estimation of net radiation from the MODIS data under all sky conditions: Southern Great Plains case study. Remote Sensing of Environment, v.114, p.1522-1534, 2010.

BISHT, G.; VENTURINI, V.; ISLAM, S.; JIANG, L. Estimation of the net radiation using MODIS (Moderate Resolution Imaging Spectroradiometer) data for clear-sky days. Remote Sensing of Environment, v.97, n.1, p.52-67, 2005.

BORGES, V. P.; OLIVEIRA, A. S.; SILVA, B. B.da. Mapeamento e quantificação de parâmetros biofísicos e radiação líquida em área de algodoeiro irrigado. Ciência Agrotécnica, v.34, n.2, p.485-493, 2010.

BRAGA, R. A. P. Gestão ambiental da bacia do rio Tapacurá - Plano de ação. Universidade Federal de Pernambuco / CTG / DECIVIL / GRH, apoio FINEP e FACEPE. Recife. $101 p, 2001$.

De BRUIN, H. A. R.; STRICKER, J. N. M. Evaporation of grass under non-restricted soil moisture conditions. Journal of Hydrology. v.45, n.3, p.391-406, 2000.
Di LONG, D.; GAO, Y.; SINGH, V. P. Estimation of daily average net radiation from MODIS data and DEM over the Baiyangdian watershed in North China for clear sky days. Journal of Hydrology, v.388, p. 217-233, 2010.

Di PACE, F. T.; SILVA, B. B.da; SILVA, V. P. R.; SILVA, S. T. A. Mapeamento do saldo de radiação com imagens Landsat 5 e modelo de elevação digital. Revista Brasileira de Engenharia Agrícola e Ambiental, v.12, p.385-392, 2008. DUARTE, C. C.; GALVÍNCIO, J. D.; CORRÊA, A. C. B.; ARAÚJO, M.S . B. Análise fisiográfica da bacia hidrográfica do rio Tapacurá. Revista de Geografia, v.24, n.2, p.50-64, 2007.

GARRISON, J. D.; ADLER, G. P. Estimation of precipitable water over the United States for application to the division of solar radiation into its direct and diffuse components. Solar Energy, v.44, p.225-241, 1990.

GOMES, H. B.; SILVA, B. B.da; CAVALCANTI, E. P.; ROCHA, H. R.da. Balanço de radiação em diferentes biomas no estado de São Paulo mediante imagens Landsat. Revista Geociências, v.28, n.2, p.153-164, 2009.

GUSMÃO, A. C. V. L.; SILVA, B. B.da; MONTENEGRO, S. M. G. L.; GALVÍNCIO, J. D. Determinação do saldo radiativo na Ilha do Bananal, TO, com imagens orbitais. Revista Brasileira de Engenharia Agrícola e Ambiental, v.16, n.10, p.1107-1114, 2012.

HUETE, A. R. A Soil adjusted vegetation index (SAVI). Remote Sensing of Environment, v.25, n.3, p.295-309, 1988.

JIN, M.; LIANG, S. An Improved Land Surface Emissivity Parameter for Land Surface Models Using Global Remote Sensing Observations. Journal of Climate, v.19, p.28672881, 2006.

JIN, Y., RANDERSON, J., GOULDEN, M. L., Continentalscale net radiation and evapotranspiration estimated using MODIS satellite observations. Remote Sensing of Environment, v.115, p.2302-2319, 2011.

KRUK, N. S.; VENDRAME, I. F.; ROCHA, H. R; CHOU, S. C.; CABRAL, O. Downward longwave radiation estimates for clear and all-sky conditions in the Sertãozinho region of São Paulo, Brazil. Theoretical and Applied Climatology, v.99, p.115-123, 2010.

LIANG, S. Narrowband to broadband conversions of land surface albedo I Algorithms. Remote Sensing of Environment, v.76, p.213-238, 2000.

LIMA, E. de P.; SEDIYAMA, G. C.; SILVA, B. B. da; GLERIANI, J. M.; SOARES, V. P. seasonality of net radiation in two sub-basins of Paracatu by the use of MODIS sensor products. Engenharia Agrícola, Jaboticabal, v.32, n.6, p.1184-1196, 2012.

MENDONÇA, J. C. Estimativa da evapotranspiração regional utilizando imagens digitais orbitais na região 
Norte Fluminense. 2007. 145p. Tese (Doutorado em Produção Vegetal) - Universidade Estadual do Norte Fluminense Darcy Ribeiro, Rio de Janeiro, 2007.

MUÑOZ-JIMÉNEZ, J. C.; SOBRINO, J. A.; GILLESPIE, A.; SABOL, D.; GUSTAFSON, W. T. Improved land surface emissivities over agricultural areas using ASTER NDVI. Remote Sensing of Environment. v.103, p.474-487, 2006.

OLIVEIRA, L. M. M.; MONTENEGRO, S. M. G. L.; ANTONINO, A. C. D.; SILVA, B. B. da; MACHADO, C. C. C.; GALVÍNCIO, J. D. Análise quantitativa de parâmetros biofísicos de bacia hidrográfica obtidos por sensoriamento remoto. Pesquisa Agropecuária Brasileira, v.47, n.9, p.1209-1217, 2012.

PRATA, A. J. A new long-wave formula for estimating downward clear-sky radiation at the surface. Quarterly Journal of the Royal Meteorological Society, v.122, p.1127-1151, 1996.

RUHOFF, A. L.; PAZ, A. R.; COLLISCHONN, W.; ARAGÃO, L. E. O. C.; ROCHA, H. R.; MALHI, Y. S. A MODIS-Based Energy Balance to Estimate Evapotranspiration for ClearSky Days in Brazilian Tropical Savannas. Remote Sensing, v.4, p.703-725, 2012.

SANTOS, F. A. C. Alterações no balanço radiativo e impactos climáticos decorrentes do uso da terra no Estado de São Paulo. 2011. 83p. Dissertação (Mestrado em Agrometeorologia e Micrometeorologia) - Universidade Federal de Campina Grande, Campina Grande, 2011.

SANTOS, C. A. C.; SILVA, B. B. da; RAO, T. V. R.; SATYAMURTI, P.; MANZI, A. O. Downward longwave radiation estimates for clear-sky conditions over Northeast Brazil. Revista Brasileira de Meteorologia, v.26, n.3, p.443-450, 2011.
SILVA, B. B. da; BRAGA, A. C.; BRAGA, C. C. Balanço de radiação no perímetro irrigado São Gonçalo - $\mathrm{PB}$ mediante imagens orbitais. Revista Caatinga, v.24, n.3, p.145-152, 2011.

SILVA, B. B. da; BRAGA, A. C.; BRAGA, C. C.; OLIVEIRA, L. M. M. de, GALVÍNCIO, J. D.; MONTENEGRO, S. M. G. L. Evapotranspiração e estimativa da água consumida em perímetro irrigado do semiárido brasileiro por sensoriamento remoto. Pesquisa Agropecuária Brasileira, v.47, n.9, p.1218-1226, 2012.

SILVA, B. B. da; LOPES, G. M.; AZEVEDO, P. V. Determinação do albedo de áreas irrigadas com base em imagens Landsat 5 - TM. Revista Brasileira de Agrometeorologia, v.13, n.2, p.201-211, 2005a.

SILVA, B. B. da; LOPES, G. M.; AZEVEDO, P. V. Balanço de radiação em áreas irrigadas utilizando imagens Landsat 5 - TM. Revista Brasileira de Meteorologia, v.20, n.2, p.243-252, 2005b.

TANG, B., Li, Z. L. Estimation of instantaneous net surface longwave radiation from MODIS cloud-free data. Remote Sensing of Environment, v.12, p.3482-3492, 2008.

ZILLMAN, J. W. A study of some aspects of the radiation and heat budgets of the southern hemisphere oceans. Meteorology Study 26, Bur. Ff Meteorology Canberra, Australia Dept. of the Inter, 1972. 